\title{
Whipple's Disease: Case Report and Review of the Literature
}

\author{
Vincenzo De Francesco ${ }^{1}$, Fabrizio Corsi ${ }^{2}$, Antonio Pennella ${ }^{2}$, Annamaria Bellesia $^{1}$, Giulia Fiorini $^{3}$, Dino Vaira ${ }^{3}$, Angelo Zullo $^{4}$
}

1) Section of Gastroenterology, Department of Medical

Sciences, Foggia;

2) Department of Pathology,

University of Foggia, Foggia;.

3) Department of

Internal Medicine and

Gastroenterology, University

of Bologna, Bologna;

4) Gastroenterology and

Digestive Endoscopy, 'Nuovo

Regina Margherita' Hospital,

Rome, Italy

\begin{abstract}
Whipple's disease (WD) is known as an infrequent, systemic, chronic infection caused by the actinomycete Tropherima whipplei (T. whipplei). The disease is frequently characterized by a long prodromal and protean extra-intestinal phase, which often causes misdiagnosis and inappropriate treatments. Herein, we describe the case a 62-year-old man with a histological diagnosis of WD established when oral steroid treatment was started due to rheumatic manifestations, triggering intestinal symptoms. Systematic review of the literature was performed to include studies where WD was eventually diagnosed on duodenal biopsies. Three patients' subgroups were identified according to the clinical presentation.
\end{abstract}

Key words: Whipple's disease - Tropherima whipplei - endoscopy - gastrointestinal tract.

Abbreviations: NSAIDs: nonsteroidal anti-inflammatory drugs; PAS: periodic acid Schiff; T. whipplei: Tropherima whipplei; WD: Whipple's disease.

\section{INTRODUCTION}

Firstly described on 1907

Address for correspondence:

Vincenzo De Francesco, MD Section of Gastroenterology, Department of Medical Sciences, University of Foggia, Ospedali Riuniti,

Viale L. Pinto,

71100 - Foggia, Italy vdefrancesco@ ospedaliriunitifoggia.it

as 'intestinal lipodystrophy', Whipple's disease (WD) is known as an infrequent, systemic, chronic infection caused by the actinomycete Tropherima whipplei (T. whipplei), suspected as aetiologic agent by PCR in 1992, and isolated by culture in 2000 . Currently, the diagnosis is mainly
Received: 04.04.2018

Accepted: 26.08.2018 performed in demonstration of periodic acid Schiff (PAS) staining positive macrophages in the lamina propria on duodenal biopsies. Indeed, the disease typically involves the small intestinal tract, causing diarrhea, weight loss, abdominal pain and fever. However, extraintestinal localizations may be present, including joints, muscleskeletal system, cardiac valves, brain, eyes, lungs, and skin. Of note, symptoms suggestive of rheumatologic disorders may anticipate digestive manifestations, not infrequently leading to a misdiagnosis and detrimental immunosuppressive treatments, as previously reported [1]. Here, we reported a case of Whipple's disease discovered at endoscopy with duodenal biopsies after longterm nonsteroidal anti-inflammatory drugs (NSAIDs) treatment and we performed a systematic review of cases eventually diagnosed at upper endoscopy with biopsy.

\section{CASE REPORT}

A 62-year-old man, poultry breeder, was referred to our Gastroenterological Unit on March 2017 because of bloody diarrhea (up to 8-10 movements/daily), abdominal pain, intermittent fever, severe fatigue, and marked weight loss $(18 \mathrm{Kg})$ during the last four months. He complained of hand and foot arthralgia in the last 9 months, initially treated with NSAIDs by his General Practitioner, without regression. Therefore, he was referred to a rheumatologist who diagnosed seronegative rheumatoid arthritis, and started a tapering therapy with $16 \mathrm{mg} /$ daily methylprednisolone and $600 \mathrm{mg}$ ibuprofen on November 2016. One month later, due to diarrhoea onset, two cycles of antibiotic therapy with rifaximin were prescribed without improvement. On the contrary, the diarrhoea became bloody so that the patient was admitted to our Unit. At entry, abdomen palpation did not reveal tenderness, and cardiac, pulmonary and neurological assessments were unrewarding. No lymphadenopathies were detected, whilst a middle hyper-pigmentation of the 
light-exposed skin was noted. Laboratory tests documented a marked microcytic anaemia (Hgb: $8 \mathrm{gr} / \mathrm{dl}$; RBC: $3.8 \times 10^{6} /$ dl, MCV: $72 \mathrm{fl}$, and ferritin: $21 \mathrm{ng} / \mathrm{dl})$, hypoalbuminaemia $(1.9 \mathrm{~g} / \mathrm{dl})$, and increased levels of both ESR $(30 \mathrm{~mm} / \mathrm{h})$ and $\beta 2$-microglobulin $(11.2 \mathrm{mg} / \mathrm{dl})$, with normal results of other routine tests. Colonoscopy was performed showing normal mucosa, but with bloody traces until the terminal ileum. Therefore, upper endoscopy was performed showing erythematosus duodenal mucosa due to diffuse haemorrhagic suffusions (Fig. 1A). Histological assessment of multiple duodenal biopsies showed large macrophage aggregates in the lamina propria, with lymphocytes and neutrophils infiltrate (Fig. 1B). PAS stain demonstrated multiple PAS-positive and diastase-resistant inclusions in foam macrophages, consistent with WD (Fig. 1C). Total body-CT scan revealed only multiple para-aortic/caval enlarged lymph nodes. Therefore, $2 \mathrm{~g}$ daily ceftriaxone therapy was administered intravenously for 2 weeks, and both anaemia and hypoalbuminaemia were corrected with intravenous supplementations. A prompt disappearance of both diarrhea and fatigue occurred during hospitalization. Thereafter, long-term oral therapy with $4 \mathrm{~g}$ daily trimethoprim-sulfamethoxazole was started, together with oral iron supplementation. On October 2017, a 9 Kg body weight gain was observed with normalization of haemoglobin levels. At repeat upper endoscopy, normal duodenal mucosa was found (Fig. 1D), whilst histological assessment showed a marked improvement, although small aggregates of foam macrophages (Fig. 1E), with rare PAS-discolored inclusions, and without neutrofils infiltrate, persisted (Fig. 1F). The patient is presently on ongoing trimethoprim-sulfamethoxazole therapy, and a further endoscopic control is planned.

\section{LITERATURE REVIEW}

A systematic review of literature was performed to include studies where WD was diagnosed at duodenal histological examination. The search was performed from January 1992 to February 2018 by using PubMed; the exploded medical subject heading terms were 'Tropherima whipplei' or 'Whipple disease. Boolean operators: NOT, AND, OR were also used in succession to narrow and widen the search. References of the retrieved articles were reviewed to search for potentially missed publications. Inclusion criterion was WD diagnosis performed on duodenal biopsies taken at upper endoscopy. A total of 559 studies were identified and, following evaluation of abstracts or full paper, 76 studies meeting the inclusion criteria were included in this pooled data analysis [2-77] (Fig. 2). Overall, there were 89 cases diagnosed with WD on duodenal biopsies, with a large prevalence of males $(\mathrm{M} / \mathrm{F}$ : $71 / 18$ ), and the mean age was $52.3 \pm 11.1$ years. Patients were mainly described in Germany (19 cases), USA (12 cases), Italy (10 cases), Brazil (9 cases), France (7 cases), Spain (5 cases), Japan and UK (4 cases), The Netherlands (3 cases), Portugal and Taiwan ( 2 cases), whilst only 1 case was reported from Austria, Australia, Balearic Isles, Belgium, Camerun, Canada, Czech Republic, Denmark, Greece, Island, Poland and Romania. Overall, intestinal symptoms were present in $60(67.4 \%)$ patients, rheumatological symptoms in $54(60.6 \%)$, ocular and neurological involvement in 15 (16.8\%), cardiac/ vascular manifestations in $14(15.7 \%)$, dermatological lesions in $12(13.4 \%)$, hematologic disorders in $11(12.3 \%)$, pulmonary symptoms in $3(8.3 \%)$ cases, and kidney involvement with amyloidosis in a single $(1.1 \%)$ case. In detail, according to the

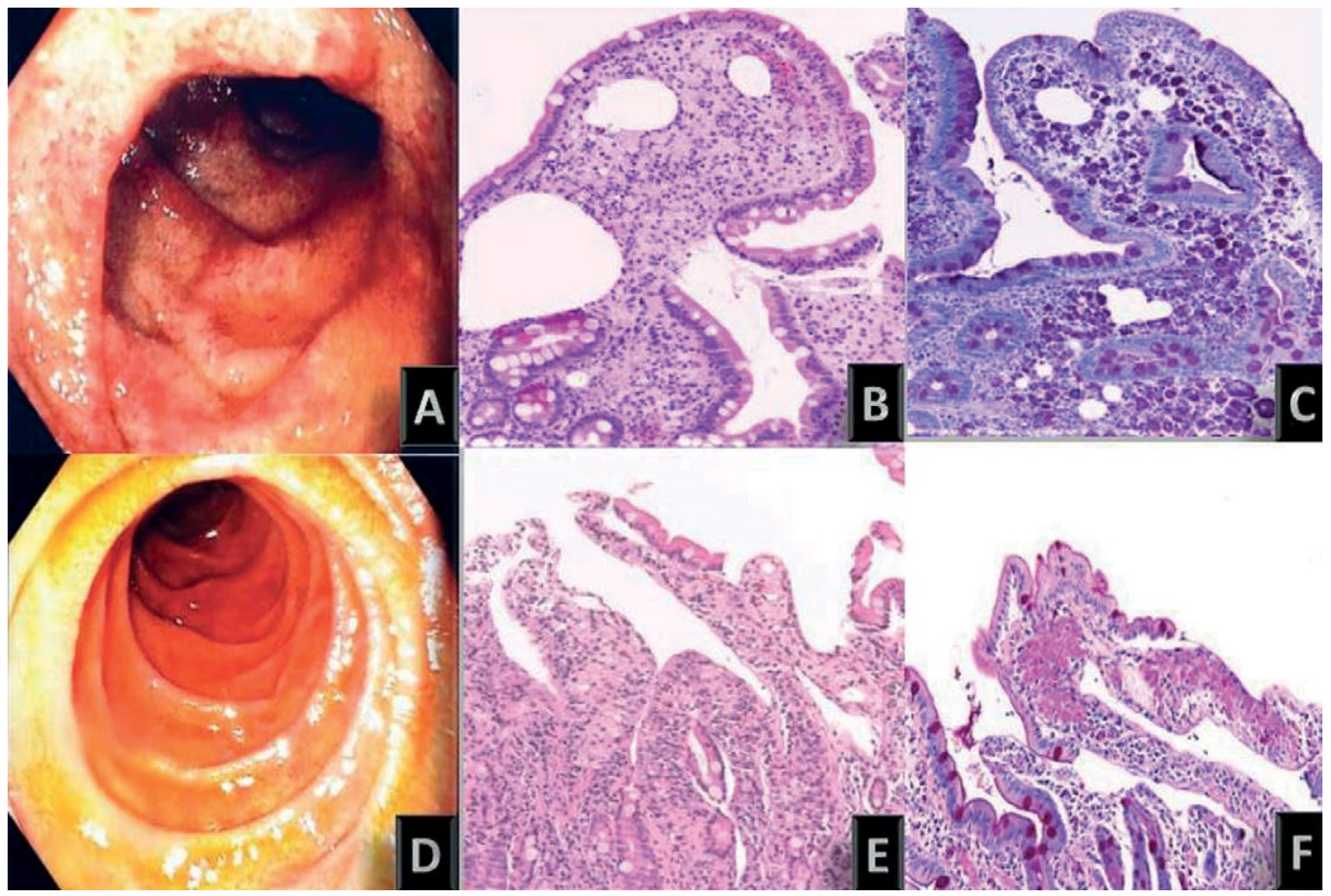

Fig. 1. Erythematosus duodenal mucosa with diffuse haemorrhagic suffusions (A). Duodenal mucosa with large macrophage aggregates in the lamina propria, with lymphocytes and neutrophils infiltrate (H\&E 200x)(B). Multiple PAS-positive and diastase-resistant inclusions in foam macrophages (C). Normal duodenal mucosa at endoscopy (D). Persistence of small aggregates of foam macrophages (H\&E 200x)(E), with rare PAS-discolored inclusions (PAS 200x)(F). 


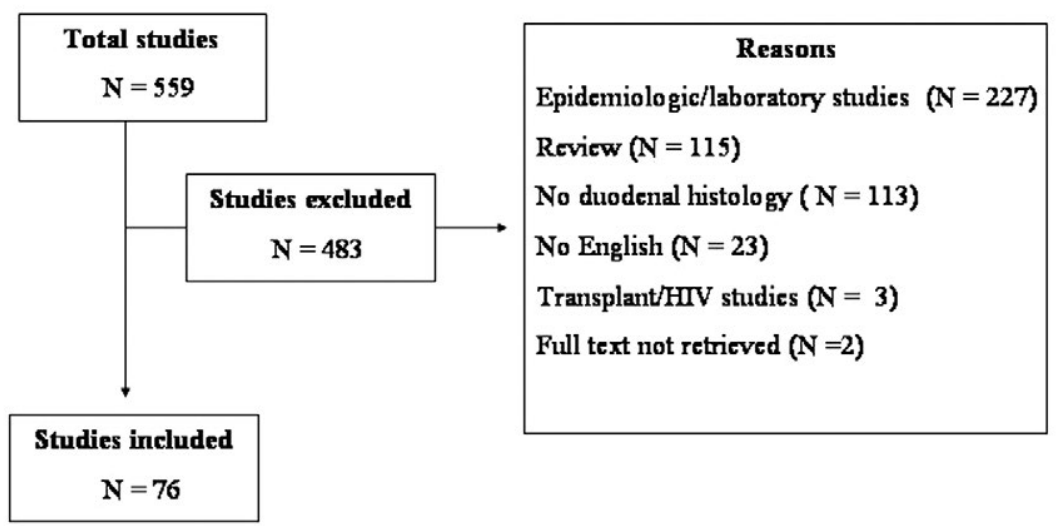

Fig. 2. Literature searching results.

clinical presentation of disease, these patients may be classified in the following three subgroups: 1) patients with early intestinal manifestations, mainly including chronic diarrhea, abdominal pain, and weight loss, suggestive of malabsorption $(\mathrm{N}=15) ; 2)$ patients with extra-intestinal manifestations (rheumatologic, neurologic, ocular, etc.) in whom a late onset of intestinal manifestations occurred, prompting upper endoscopy $(\mathrm{N}=$ 45); and 3) patients with extra-intestinal manifestations, but without intestinal symptoms, in whom upper endoscopy was occasionally performed as work-up before NSAIDs or steroid therapy starting $(\mathrm{N}=29)$. Of note, early appearance of intestinal symptoms significantly anticipated diagnosis (Table I).

Table I. Clinical characteristics of patients according to the initial clinical presentation.

\begin{tabular}{lccc}
\hline & $\begin{array}{c}\text { Early } \\
\text { intestinal } \\
(\mathrm{N}=15)\end{array}$ & $\begin{array}{c}\text { Extra- } \\
\text { intestinal and } \\
\text { late intestinal } \\
(\mathrm{N}=45)\end{array}$ & $\begin{array}{c}\text { Extra- } \\
\text { intestinal only } \\
(\mathrm{N}=29)\end{array}$ \\
\hline Male/Female & $11 / 4$ & $37 / 8$ & $24 / 5$ \\
Age (Mean \pm SD);years & $51.1 \pm 8.3$ & $53.5 \pm 12.5$ & $51 \pm 10.2$ \\
$\begin{array}{l}\text { Diagnosis interval; } \\
\text { median (range); months }\end{array}$ & $8(1-48)^{1}$ & $24(24-264)$ & $30(1-240)$ \\
$\begin{array}{l}\text { Disease regression (\%) } \\
\text { Recurrence (\%) }\end{array}$ & $12(80)$ & $43(96)$ & $21(72)$ \\
\hline
\end{tabular}

${ }^{1}$ Statistical difference $(\mathrm{p}<0.001)$ among early intestinal with the other groups (Mann-Whitney test); ${ }^{2}$ Statistical difference $(\mathrm{p}<0.05)$ among extra-intestinal only with the other groups. (Fisher's exact test).

The most frequently used therapy was intravenous ceftriaxone for 14 days followed by long-term oral trimethoprimsulfamethoxazole (77 cases; 86.5\%; median duration: 12 months, range: 6-24), whilst different combinations with an aminoglycoside, cotrimoxazole, tetracycline were used in the remaining 12 cases. Overall, clinical remission was achieved in 76 patients, and the success rate was significantly higher for ceftriaxone followed by trimethoprim-sulfamethoxazole therapy as compared to other performed therapies $(89.6 \%$ vs $58.3 \%$, p < 0.05 ; OR: 6.1, 95\% CI = 1.5-24). Recurrence of disease occurred in 13 (17\%) cases, during a 1-12 years follow up, and $8(61.5 \%)$ of these patients were successfully re-treated whilst the remaining 5 cases were lost at follow-up. The recurrence rate was significantly higher in patients without intestinal symptoms $(8 / 21,28 \%)$ as compared to those patients with early/late intestinal symptoms $(5 / 60,8 \%)$ (Table I).

\section{DISCUSSION}

Whipple's disease is a chronic systemic infection caused by T. whipplei, generally in the presence of a defective cellular immune response [78]. A higher incidence of the infection among breeders and sewage workers has been reported, suggesting an occupational or environmental method of transmission $[49,79-81]$. It is a rare disease, with protean clinical presentation, including intestinal and extra-intestinal symptoms, with consequent misdiagnosis [2]. Rheumatologic manifestations might precede intestinal symptoms, which develop when immunosuppressive therapy is introduced, as occurred in our patient and in other reports $[2,13,82$, 83]. Therefore, the onset of intestinal manifestations during immunosuppressive therapy should alert the physicians, particularly in those patients with occupational risk factors for WD. By reviewing data of literature, we found that diagnosis was performed only following several months from symptoms onset, further suggesting that this is an insidious and still neglected disease. Noteworthy, we found that WD was incidentally diagnosed at duodenal biopsies in as many as $38 \%$ of patients with extra-intestinal manifestations (arthritis, neurological symptoms, cardio-vascular, ocular disorders), but without gastrointestinal symptoms. Indeed, the presence of gastrointestinal symptoms significantly reduces the diagnostic delay from 30 to 8 months in the considered case series.

Differently from several bacterial species, culture of $T$. whipplei is very difficult and time-consuming because of the very slow bacterial grow. Therefore, diagnosis of WD is currently performed by PAS staining on duodenal biopsies. Nevertheless, the reliability of the PAS testing may be mined in a significant number of cases either by false positive results, particularly in the course of other infections (HIV, histoplasmosis, mycosis, etc.) or false negative findings during immunosuppressive treatment [84]. For these reasons, a PCRbased tool, performed on organ biopsies or different body fluids, may be necessary for diagnosing or confirming WD in some cases. Indeed, the PCR allows the detection of specific 
bacterial 16S rRNA. More recently, a quantitative real-time PCR tool was found to have a higher sensitivity than a standard PCR, but this method is available only in a few centers [2, $28,85]$. Seldom, Tropheryma presence in biologic fluids was confirmed by the finding of the peculiar trilamellar cell wall at electron microscopy [2]. Finally, a PET-based technique was associated with a high diagnostic yield when cerebral localization was present [86].

The most frequently used treatment included a 2-week intravenously cephalosporins followed by oral sulphamides for 1-2 years. We found that this therapy achieved significantly higher success rate when compared to the others, with values approaching 90\%. However, long-term therapy and followup are required, particularly in those patients with a longer misdiagnosis or presence of extra-intestinal involvement who are at an increased risk of treatment failure [87]. In this series, the infection recurrence rate was as high as $17 \%$. Of note, we computed that those patients with only extra-intestinal symptoms had a recurrence more frequently than other patients.

\section{CONCLUSIONS}

Whipple's disease is a rare and ubiquitous infectious disease, presenting with different and protean manifestations. Presence of gastrointestinal symptoms significantly reduces the diagnostic delay, but they are lacking in more than one third of cases. Long-term antibiotic treatment achieves high success rates.

Conflicts of interest: None to declare.

Authors' contribution: V.d.F. and A.Z. designed and wrote the manuscript. A.B. and G.F. collected literature data. F.C. and A.P. performed histological assessment and evaluations. D.V. reviewed with constructive criticisms.

\section{REFERENCES}

1. Lepidi H, Fenollar F, Gerolami R, et al. Whipple's disease: immunospecific and quantitative immunohistochemical study of intestinal biopsy specimens. Hum Pathol 2003;34:589-596. doi:10.1016/S00468177(03)00126-6

2. Saito H, Shiode J, Ohya S, et al. Whipple's Disease: A Case Report with Long-term Endoscopic Follow-up. Intern Med 2018;57:1707-1713. doi:10.2169/internalmedicine.9631-17

3. Loiodice A, Losurdo G, Iannone A, Rossi R, Fiore MG, Piscitelli D. Transmission electron microscopy helpfulness in Whipple's disease masked by immunosuppressant therapy for arthritis. APMIS 2018;126:92-96. doi:10.1111/apm.12782

4. Heavener T, Thompson M, Patel C, Forrester L, Rawls D. An unusual presentation of Tropheryma whipplei infection. Proc (Bayl Univ Med Cent) 2017;30:429-430.

5. Seddon O, Hettiarachchi I. Whipple's endocarditis presenting as ulnar artery aneurysm; if you don't look, you won't find. BMJ Case Rep 2017. doi:10.1136/bcr-2017-221327

6. Glaser C, Rieg S, Wiech T, et al. Whipple's disease mimicking rheumatoid arthritis can cause misdiagnosis and treatment failure. Orphanet J Rare Dis 2017;12:99. doi:10.1186/s13023-017-0630-4
7. Parkash V, Mudhar HS, Wagner BE, et al. Bilateral Ocular Myositis Associated with Whipple's Disease. Ocul Oncol Pathol 2017;3:17-21. doi: $10.1159 / 000448622$

8. Henriques MS, da Paz AR, Gaertner AB, Melo CI, Filgueiras PL, Jerome RA. Deep Vein Thrombosis as Initial Manifestation of Whipple Disease. Case Rep Gastroenterol 2016;10:640-645. doi:10.1159/000452206

9. Ruggiero E, Zurlo A, Giantin V, et al. Relapsing Whipple's disease:a case report and literature review. Eur J Gastroenterol Hepatol 2016;28:267270. doi:10.1097/MEG.0000000000000539

10. Peregrin J, Malikova H. Primary Whipple disease of the brain:case report with long-term clinical and MRI follow-up. Neuropsychiatr Dis Treat 2015;11:2461-2469. doi:10.2147/NDT.S92066

11. Rezk A, Gunnerson AC, Komar M. A Disease That Is Often Missed Without Gastrointestinal Symptoms. Gastroenterology 2016;150:10961097. doi:10.1053/j.gastro.2015.11.054

12. Perez-Alvarez I, Yekezare S, Zhao XF, Xu X. Atypical presentation of Whipple disease with no diarrhea. Indian J Pathol Microbiol 2015;58:398-399. doi:10.4103/0377-4929.162930

13. Ramos JM, Pasquau F, Galipienso N, et al. Whipple's disease diagnosed during anti-tumor necrosis factor alpha treatment: two case reports and review of the literature. J Med Case Rep 2015;9:165. doi:10.1186/ s13256-015-0632-6

14. Martínez-Sánchez A, Sánche-Ceballos FL, Fernández-Díez S, et al. Atypical diagnosis diagnosis by endoscopic capsule:Whipple's disease. Rev Esp Enferm Dig 2016;108:158-162. doi:10.17235/ reed.2015.3718/2015

15. Silva GA, Neto JS. Whipple's disease manifested as difficult-to-diagnose polyarthralgia: a case report and literature review. Rev Bras Reumatol 2015;57:483-486. doi:10.1016/j.rbr.2014.12.014

16. Magalhães-Costa $P$, Chagas C. Purpura in the duodenum. Gastroenterology 2015;148:910-911. doi:10.1053/j.gastro.2014.12.044

17. Jensen MB, Stawowy M, Christiansen J. Whipple's disease in an elderly patient with a substantial weight loss and gastrointestinal symptoms. Ugeskr Laeger 2014;176:V12120724.

18. Sutherland RK, Russell KV, Trivedi PJ, Warren B, Smith RW, Conlon CP. A constricting differential--a case of severe anaemia, weight loss and pericarditis due to Tropheryma whipplei infection. QJM 2014;107:927929. doi:10.1093/qjmed/hcs041

19. Gaïni S, Bruun NE, Kollslíð R, et al. Whipple's disease involving the eye, the brain, the heart and the gut diagnosed through the eye. Acta Ophthalmol 2014;92:e693-694. doi:10.1111/aos.12454

20. Sulis G, Villanacci V, Missale G, Salemme M, Castelli F, Caligaris S Whipple's disease concomitant with candida esophagitis and subsequent Giardia lamblia coinfection. Eur J Gastroenterol Hepatol 2014;26:11811185. doi:10.1097/MEG.0000000000000154

21. Tun NT, Shukla S, Krishnakurup J, Pappachen B, Krishnamurthy M, Salib H. An unusual cause of pancytopenia: Whipple's disease. J Community Hosp Intern Med Perspect 2014;4. doi:10.3402/jchimp. $\mathrm{v} 4.23482$

22. Costa JH, Maciel AB, Godinho Mde N, Paula RB, Gotardelo DR Tumoural form of Whipple's disease simulating carcinomatosis. Braz J Infect Dis 2014;18:346-349. doi:10.1016/j.bjid.2014.01.006

23. Loughran D, Beale L, Lodge F, Habboush H, Stock D. Whipple's in the valleys: a case of Whipple's with thrombocytopenia and endocarditis. J Clin Pathol 2014;67:445-448. doi:10.1136/jclinpath-2013-201915

24. Gervaise A, Corberand D, Naulet P, Pernin M, Portron Y, LapierreCombes M. Whipple's disease with gastrointestinal involvement and multiple abdominal adenopathies. Diagn Interv Imaging 2013;94:11451147. doi:10.1016/j.diii.2013.04.007 
25. Amendolara M, Barbarino C, Bucca D, et al. Whipple's disease infection surgical treatment:presentation of a rare case and literature review. G Chir 2013;34:117-121.

26. Fenollar F, Lagier JC, Rolain JM, et al. Tropheryma whipplei endocarditis relapses after treatment with trimethoprim/sulfamethoxazole. Int J Antimicrob Agents 2013;41:592-594. doi:10.1016/j. ijantimicag.2013.02.003

27. Hoskote SS, Georgescu A, Ganjhu L, Zeizafoun N, Polsky B. Resolution of whipple disease-induced pulmonary hypertension following antibiotic therapy. Am J Ther 2014;21:e143-e147. doi:10.1097/ MJT.0b013e3182691cdc

28. Yajima N, Wada R, Kimura S, et al. Whipple disease diagnosed with PCR using formalin-fixed paraffin-embedded specimens of the intestinal mucosa. Intern Med 2013;52:219-222. doi:10.2169/ internalmedicine.52.8642

29. Mateescu BR, Bengus A, Marinescu M, Staniceanu F, Micu G, Negreanu L. First Pillcam Colon 2 capsule images of Whipple's disease:Case report and review of the literature. World J Gastrointest Endosc 2012;4:575578. doi:10.4253/wjge.v4.i12.575

30. Algin A, Wegdam-Blans M, Verduin K, Janssen H, van Dantzig JM. Tropheryma whipplei aortic valve endocarditis, cured without surgical treatment. BMC Res Notes 2012;5:600. doi:10.1186/1756-0500-5-600

31. Renon VP, Appel-da-Silva MC, D'Incao RB, Lul RM, Kirschnick LS, Galperim B. Whipple's disease: rare disorder and late diagnosis. Rev Inst Med Trop Sao Paulo 2012;54:293-297. doi:10.1590/S003646652012000500010

32. Uryu K, Sakai T, Yamamoto T, et al. Central nervous system relapse of Whipple's disease. Intern Med 2012;51:2045-2050. doi:10.2169/ internalmedicine.51.7304

33. Weisfelt M, Oosterwerff E, Oosterwerff M, Verburgh C. Whipple's disease presenting with neurological symptoms in an immunosuppressed patient. BMJ Case Rep 2012;2012:bcr0220125882. doi:10.1136/ bcr.02.2012.5882

34. Urbanski G, Rivereau P, Artru L, Fenollar F, Raoult D, Puéchal $\mathrm{X}$. Whipple disease revealed by lung involvement:a case report and literature review. Chest 2012;141:1595-1598. doi:10.1378/ chest.11-1812

35. von Gerstenbergk C, Lorenz HM, Blank N. Fever and arthritis: rheumatic or Whipple's disease? Dtsch Med Wochenschr 2011;136:1656-1659. doi:10.1055/s-0031-1281569

36. Vangoitsenhoven R, Nijs J, Verbrugge H, Van Meerbeek J, Van den Bergh L. Whipple's disease. A classic case report and review of the literature. Acta Gastroenterol Belg 2010;73:392-396.

37. Jubany LI, Selva-O'Callaghan A, Pérez-Vega C, Grau-Junyent JM, Hernández-Losa J, Vilardell-Tarrés M. The patient has the diagnosis. Lancet 2010;376:1436. doi:10.1016/S0140-6736(10)61049-5

38. Wientjes CA, Luykx-de Bakker SA, Prins ME, Lobatto S. Unexplained lymphadenopathy:Whipple disease. Ned Tijdschr Geneeskd 2009;153:B497.

39. Niemczyk S, Filipowicz E, Wozniacki L, et al. Renal amyloidosis in Whipple disease: a case report. Cases J 2009;2:8444. doi:10.4076/17571626-2-8444

40. De Francesco V, Zullo A, Cristofari F, et al. A juvenile, misdiagnosed case of Whipple's disease. Rheumatol Int 2009;30:143-144. doi:10.1007/ s00296-009-1004-6

41. Schaller J, Carlson JA. Erythema nodosum-like lesions in treated Whipple's disease: signs of immune reconstitution inflammatory syndrome. J Am Acad Dermatol 2009;60:277-288. doi:10.1016/j. jaad.2008.09.024
42. Lyle PL, Weber RD, Bogarin J, Kircher T. Reversible pulmonary hypertension in Whipple disease: a case report with clinicopathological implications, and literature review. BMJ Case Rep 2009;2009:bcr06.2008.0095. doi:10.1136/bcr.06.2008.0095

43. Berent R, Auer J, Lassnig E, et al. Whipple's disease: misdiagnosed as sarcoidosis with further tricuspid valve endocarditis and pulmonary embolism - a case report. BMJ Case Rep 2009;2009:bcr07.2008.0441. doi:10.1136/bcr.07.2008.0441

44. Mancini F, Sbaragli S, Colivicchi G, Cassone A, Ciervo A. Fourteen years of severe arthralgia in a man without gastrointestinal symptoms: atypical Whipple's disease. J Clin Microbiol 2009;47:492-495. doi:10.1128/ JCM.01833-08

45. Schijf LJ, Becx MC, de Bruin PC, van der Vegt SG. Whipple's disease: easily diagnosed, if considered. Neth J Med 2008;66:392-395.

46. Marumganti AR, Murphy TF. Whipple's disease: neurological relapse presenting as headache for two years. J Gen Intern Med 2008;23:21312133. doi:10.1007/s11606-008-0776-9

47. Lo Monaco A, Govoni M, Zelante A, et al. Whipple disease: unusual presentation of a protean and sometimes confusing disease. Semin Arthritis Rheum 2009;38:403-406. doi:10.1016/j.semarthrit.2008.03.007

48. Gundling F, Wittenburg H, Tannapfel A, Mossner J. Neurological presentation of Whipple's disease after long-term antibiotic treatment: a case report. J Med Case Rep 2008;2:191. doi:10.1186/1752-1947-2-191

49. Kremer AE, Budenhofer U, Beuers U, Rust C. A 47-year-old dog breeder with chronic polyarthritis, weight loss and high fever. Z Gastroenterol 2008;46:431-434. doi:10.1055/s-2007-963690

50. Cremniter J, Bauer T, Lortat-Jacob A, et al. Prosthetic hip infection caused by Tropheryma whipplei. J Clin Microbiol 2008;46:1556-1557. doi:10.1128/JCM.02451-07

51. Vincent V, Zabraniecki L, Uro-Coste E, Lemaire O, Fournié B. Whipple disease revealed by musculocutaneous symptoms, with muscle biopsy cultures positive for Tropheryma whipplei. Joint Bone Spine 2007;74:506-508. doi:10.1016/j.jbspin.2007.05.002

52. Puéchal X, Fenollar F, Raoult D. Cultivation of Tropheryma whipplei from the synovial fluid in Whipple's arthritis. Arthritis Rheum 2007;56:1713-1718. doi:10.1002/art.22596

53. Al-Hamoudi W, Habbab F, Nudo C, Nahal A, Flegel K. Eosinophilic vasculitis:a rare presentation of Whipple's disease. Can J Gastroenterol 2007;21:189-191.

54. Prüss H, Katchanov J, Zschenderlein R, Loddenkemper C, Schneider T, Moos V. A patient with cerebral Whipple disease with gastric involvement but no gastrointestinal symptoms: a consequence of local protective immunity? J Neurol Neurosurg Psychiatry 2007;78:896-898. doi:10.1136/jnnp.2006.110908

55. Juárez Y, España S, Fernández-Díaz ML, Lueiro M. Scurvy and acquired ichthyosis associated to Whipple's disease. Actas Dermosifiliogr 2006;97:587-590. doi:10.1016/S0001-7310(06)73472-X

56. Maia LF, Marta M, Lopes V, et al. Hypersomnia in Whipple disease: case report. Arq Neuropsiquiatr 2006;64:865-868. doi:10.1590/S0004282X2006000500030

57. Prendki V, Grandière-Perez L, Ansart S, Fenollar F, Bricaire F, Caumes E. Tropical sprue in two foreign residents, with evidence of Tropheryma whipplei in one case. J Travel Med 2006;13:175-177. doi:10.1111/j.17088305.2006.00038.x

58. Tran HA. Reversible hypothyroidism and Whipple's disease. BMC Endocr Disord 2006;6:3. doi:10.1186/1472-6823-6-3

59. Saba M, Rollot F, Park S, et al. Whipple disease, initially diagnosed as sarcoidosis. Presse Med 2005;34:1521-1524. doi:10.1016/S07554982(05)84217-4 
60. Kneitz C, Suerbaum S, Beer M, Müller J, Jahns R, Tony HP. Exacerbation of Whipple's disease associated with infliximab treatment. Scand J Rheumatol 2005;34:148-151. doi:10.1080/03009740510015230

61. Papadopoulou M, Rentzos M, Vagiakis E, et al. An unusual case of insomnia associated with Whipple encephalopathy: first case reported from Greece. Neurol Sci 2005;26:174-177. doi:10.1007/s10072-005-0457-y

62. Famularo G, Minisola G, De Simone C. A patient with cerebral Whipple's disease and a stroke-like syndrome. Scand J Gastroenterol 2005;40:607609. doi:10.1080/00365520510015494

63. Yogi T, Hokama A, Kinjo F, et al. Whipple's disease:the first Japanese case diagnosed by electron microscopy and polymerase chain reaction. Intern Med 2004;43:566-570. doi:10.2169/internalmedicine.43.566

64. França MC Jr, Castro Rd, Balthazar ML, et al. Whipple’s disease with neurological manifestations: case report. Arq Neuropsiquiatr 2004;62:342-346. doi:10.1590/S0004-282X2004000200028

65. Bosman C, Boldrini R, Borsetti G, Morelli S, Paglia MG, Visca P. Sicca syndrome associated with Tropheryma whipplei intestinal infection. J Clin Microbiol 2002;40:3104-3106. doi:10.1128/JCM.40.8.3104-3106.2002

66. Peschard S, Brinkane A, Bergheul S, et al. Whipple disease associated with pulmonary arterial hypertension. Jarisch-Herxheimer reaction after antibiotic therapy. Presse Med 2001;30:1549-1551.

67. Caples SM, Petrovic LM, Ryu JH. Successful treatment of Whipple disease diagnosed 36 years after symptom onset. Mayo Clin Proc 2001;76:1063-1066. doi:10.4065/76.10.1063

68. Walter R, Bachmann SP, Schaffner A, Rüegg R, Schoedon G. Bone marrow involvement in Whipple's disease: rarely reported, but really rare? Br J Haematol 2001;112:677-679. doi:10.1046/j.13652141.2001.02648.x

69. Ferrari Mde L, Vilela EG, Faria LC, et al. Whipple's disease. Report of five cases with different clinical features. Rev Inst Med Trop Sao Paulo 2001;43:45-50. doi:10.1590/S0036-46652001000100009

70. Caserta I, Esposito P, Russo F, et al. Whipple's disease. Description of a case and survey of the literature. Minerva Gastroenterol Dietol 2000;46:105-112.

71. Mohm J, Naumann R, Schuler U, Ehninger G. Abdominal lymphomas, convulsive seizure and coma: a case of successfully treated, advanced Whipple's disease with cerebral involvement. Eur J Gastroenterol Hepatol 1998;10:893-895.

72. Williams JG, Edward DP, Tessler HH, Persing DH, Mitchell PS, Goldstein DA. Ocular manifestations of Whipple disease: an atypical presentation. Arch Ophthalmol 1998;116:1232-1234. doi:10.1001/ archopht.116.9.1232

73. Petrides PE, Müller-Höcker J, Fredricks DN, Relman DA. PCR analysis of T. whippelii DNA in a case of Whipple's disease: effect of antibiotics and correlation with histology. Am J Gastroenterol 1998;93:1579-1582. doi:10.1111/j.1572-0241.1998.00416.x
74. Nishimura JK, Cook BE Jr, Pach JM. Whipple disease presenting as posterior uveitis without prominent gastrointestinal symptoms. Am J Ophthalmol 1998;126:130-132. doi:10.1016/S0002-9394(98)00084-1

75. Schneider T, Salamon-Looijen M, von Herbay A, et al. Whipple's disease with aortic regurgitation requiring aortic valve replacement. Infection 1998;26:178-180. doi:10.1007/BF02771847

76. Rickman LS, Freeman WR, Green WR, et al. Brief report: uveitis caused by Tropheryma whippelii (Whipple's bacillus). N Engl J Med 1995;332:363-366. doi:10.1056/NEJM199502093320604

77. Meier-Willersen HJ, Maiwald M, von Herbay A. Whipple's disease associated with opportunistic infections. Dtsch Med Wochenschr 1993;118:854-860. doi:10.1055/s-2008-1059397

78. Schneider T, Moos V, Loddenkemper C, Marth T, Fenollar F, Raoult D. Whipple's disease:new aspects of pathogenesis and treatment. Lancet Infect Dis 2008;8:179-190. doi:10.1016/S1473-3099(08)70042-2

79. Schöniger-Hekele M, Petermann D, Weber B, Müller C. Tropheryma whipplei in the environment: survey of sewage plant influxes and sewage plant workers. Appl Environ Microbiol 2007;73:2033-2035. doi:10.1128/ AEM.02335-06

80. Fenollar F, Marth T, Lagier JC, Angelakis E, Raoult D. Sewage workers with low antibody responses may be colonized successively by several Tropheryma whipplei strains. Int J Infect Dis 2015;35:51-55. doi:10.1016/j.ijid.2015.04.009

81. Fenollar F, Keita AK, Buffet S, Raoult D. Intrafamilial circulation of Tropheryma whipplei, France. Emerg Infect Dis 2012;18:949-955. doi:10.3201/eid1806.111038

82. Marth T, Raoult D. Whipple's disease. Lancet 2003;361:239-246. doi:10.1016/S0140-6736(03)12274-X

83. Mahnel R, Kalt A, Ring S, Stallmach A, Strober W, Marth T Immunosuppressive therapy in Whipple's disease patients is associated with the appearance of gastrointestinal manifestations. Am J Gastroenterol 2005;100:1167-1173. doi:10.1111/j.1572. 0241.2005.40128.x

84. Marth T. Systematic review: Whipple's disease (Tropheryma whipplei infection) and its unmasking by tumour necrosis factor inhibitors. Aliment Pharmacol Ther 2015;41:709-724. doi:10.1111/apt.13140

85. Dick J, Krauß P, Hillenkamp J, Kohlmorgen B, Schoen C. Postoperative Tropheryma whipplei endophthalmitis - a case report highlighting the additive value of molecular testing. JMM Case Rep 2017;4:e005124. doi:10.1099/jmmcr.0.005124

86. Lagier JC, Fenollar F, Koric L, Guedj E, Ceccaldi M, Raoult D. Weight loss, dementia and ataxia susceptible to doxycycline:a likely new case report caused by T. whipplei. Rev Med Interne 2013;34:641-644 doi:10.1016/j.revmed.2012.12.006

87. Fenollar F, Puéchal X, Raoult D. Whipple's disease. N Engl J Med 2007;356:55-66. doi:10.1056/NEJMra062477 